\title{
Numerical Simulation of Blast Loaded CFRP Retrofitted Steel Plates
}

\author{
Mujtaba M. Shuaib ${ }^{1}$, Steeve Chung Kim Yuen ${ }^{1 *}$, and Gerald N. Nurick ${ }^{1}$ \\ ${ }^{1}$ Blast Impact and Survivability Research Unit (BISRU), Department of Mechanical Engineering, \\ University of Cape Town, Private Bag, Rondebosch 7701, South Africa
}

\begin{abstract}
This paper reports on the results of a numerical study to simulate the response of carbon fibre reinforced polymer (CFRP) retrofitted steel plates to applied blast loads using finite element software, LS-DYNA. The results of the simulation were validated against plate response and magnitude of deformation obtained from previous experiments. The uniform blast load was generated in the experiment by detonating a cylindrical charge down the end of a square tube. The finite element code LS-DYNA was used to simulate the structural response of the respective blast structures. For the numerical model, the blast load was simulated using the mapping feature available in LS-DYNA for the multi-material arbitrary Lagrangian-Eulerian (MM-ALE) elements which significantly reduced the size of the air domain in the model. The simulations showed a satisfactory correlation with the experiments for the blast results and post-failure deformations that occurred in CFRP retrofitted steel plates.
\end{abstract}

\section{Introduction}

Structural retrofitting with fibre reinforced polymer (FRP) composites has been widely used to repair a range of deteriorated existing structures such as bridges and pipelines in oil and gas industry. FRP retrofitting has several advantages, including the high stiffness- and strength-to-weight ratios, good corrosion resistance, and shape flexibility of FRP laminates [1-3]. The use of FRP for strengthening is common in concrete structures, and it has recently been used to retrofit existing steel structures. Several studies have shown that FRP retrofitting enhances the flexural capabilities, ultimate loading capacity, and lateral impact resistance of steel structural elements [2]. Carbon fibre reinforced polymers (CFRPs) are one of the most commonly used FRPs, and they are preferred for improving the resistance of structural members due to their significantly higher elasticity modulus and tensile strength [4].

FRP retrofitting can provide a viable method for protecting existing structures from extreme loading conditions such as impact and blast. The resistance of FRP retrofitted structures to blast loads has been investigated with a focus on concrete and masonry structural elements such as slabs and walls $[5,6]$. For metals, despite significant study on the structural response of fibre-metal laminates (FMLs) to blast loads [7], few studies have been found to investigate the potential of FRP retrofitting to mitigate the damage of blast-loaded FRP retrofitted metallic structures [2,8]. Bambach et al. [9] conducted experimental and analytical

* Corresponding author: steeve.chungkimyuen@uct.ac.za 
studies on the energy-absorbing characteristics of CFRP strengthened aluminium beams under the transverse blast. A remarkable decrease up to $30 \%$ was observed in deflections due to CFRP strengthening of the aluminium beams. Previous research $[10,11]$ has demonstrated through experiment and numerical analysis that reinforcing steel pipes with sufficient CFRP thicknesses considerably increases their resilience to external blast.

Numerical simulation using finite element method (FEM) has been widely used to assess the mechanical response of fibre-based polymer composites to impact and blast loads [7]. For blast loading, research has been carried out using several commercial FEM software packages (e.g., LS-DYNA and ABAQUS) to simulate the response of composite structures to impulsive loadings [12]. Karagiozova et al. [13], Sitnikova et al. [14] and Li et al. [15] investigated numerically the response of fibre-metal laminates to high impulsive blast loading, and found a good agreement between numerical and experimental modes of failure.

This paper evaluates numerically the potential of FRP retrofitting to mitigate deformations in blast-loaded metal plates while maintaining additional strength. LS-DYNA was used to develop a numerical model that was validated with previous experiments. The paper discusses a number of potential finite element methods in LS-DYNA for simulating the response of composite structures subjected to blast loads.

\section{Experiment Setup}

The configuration of the experiment is shown in Fig. 1. Specimens of CFRP retrofitted steel plate were prepared for experimental testing. In addition to retrofitted specimens, bare steel plates were tested as a baseline to assess the performance of the retrofitted CFRP. The steel plates used were made of high-strength low-alloy (HSLA) steel and cut in $300 \times 300$ $\mathrm{mm}$ quadrangles with $1 \mathrm{~mm}$ thickness. The steel plates used were made of high-strength lowalloy (HSLA) steel (205.9 GPa modulus of elasticity, 275.4 MPa yield strength, and 353.1 MPa ultimate tensile strength - obtained from uni-axial tensile tests). An area of $200 \times 200$ $\mathrm{mm}$ was exposed to the blast loading where the outer edges were clamped. The uniform blast loads were generated by detonating plastic explosives (PE4) ranging between $7 \mathrm{~g}$ and $19 \mathrm{~g}$ in $40 \mathrm{~mm}$ cylindrical discs. $1 \mathrm{~g}$ of explosive was used to attach the detonator to the centre of the disc of explosive. Unidirectional (UD) CFRP composite sheets were used and bonded to one side of the steel plate. Two fibre-configurations of 3 and 4 layers of carbon fibre laid longitudinally were applied in the retrofitted specimens. Epoxy-based resin was used between each layer to maintain adhesion in steel-CFRP and CFRP-CFRP interfaces.

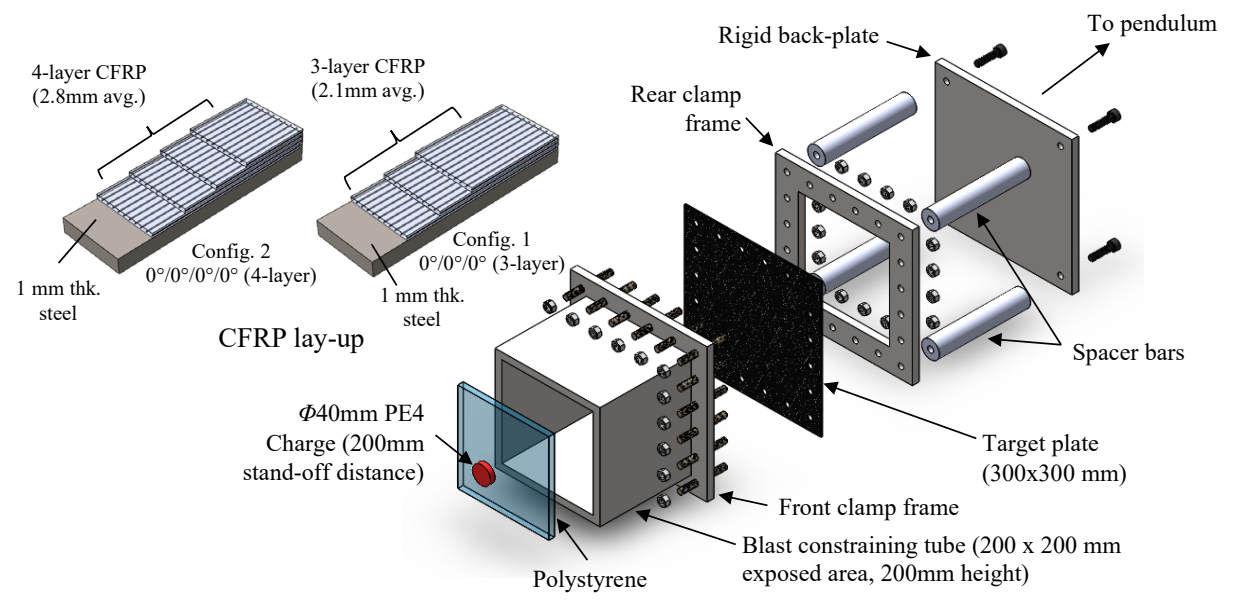

Fig. 1. Schematic representation of the experimental setup 


\section{Model Description}

LS-DYNA finite element software was used to numerically simulate the structural response of CFRP retrofitted steel plates to uniform blast loading. Fig. 2 illustrates the model components, which mainly consisted of a target plate (bare steel or CFRP retrofitted steel plate), an air domain, an explosive charge, a steel clamping frame, and steel bolts for frame fixing. To reduce computational time, one-quarter of the plate was modelled, and one-quarter symmetry boundary conditions were applied to nodes intersecting the symmetry planes. The clamping frame and bolts were considered as rigid parts with fixed boundary conditions.

Blast pressures were applied on a reduced air domain using the mapping feature offered in LS-DYNA for arbitrary Lagrangian-Eulerian (ALE) elements [16, 17]. The ALE mapping approach was applied in a manner similar to the ALE coupling method developed by Salvik [18], where the only the air adjacent to the Lagrangian structures was considered. As illustrated in Fig. 2 (a), the air-blast was first simulated by explicitly modelling the air and explosive with the multi-material arbitrary Lagrangian-Eulerian (MM-ALE). Pressure data from a selected ALE mapping layer in the simulated full air-domain model (Fig. 2(a)) were saved into a mapping output file using the ALE mapping feature. The generated mapping file was then used as an input in the reduced air-domain model, with the saved pressure imposed in the mapping layer (Fig. 2 (b)). Fluid-structure interaction (FSI) was used for communication between the target plate and the ALE domain. To simulate the openings in the blast constraining tube used in the experiment, non-reflecting boundary conditions were assigned at the top and bottom of the air-domain.

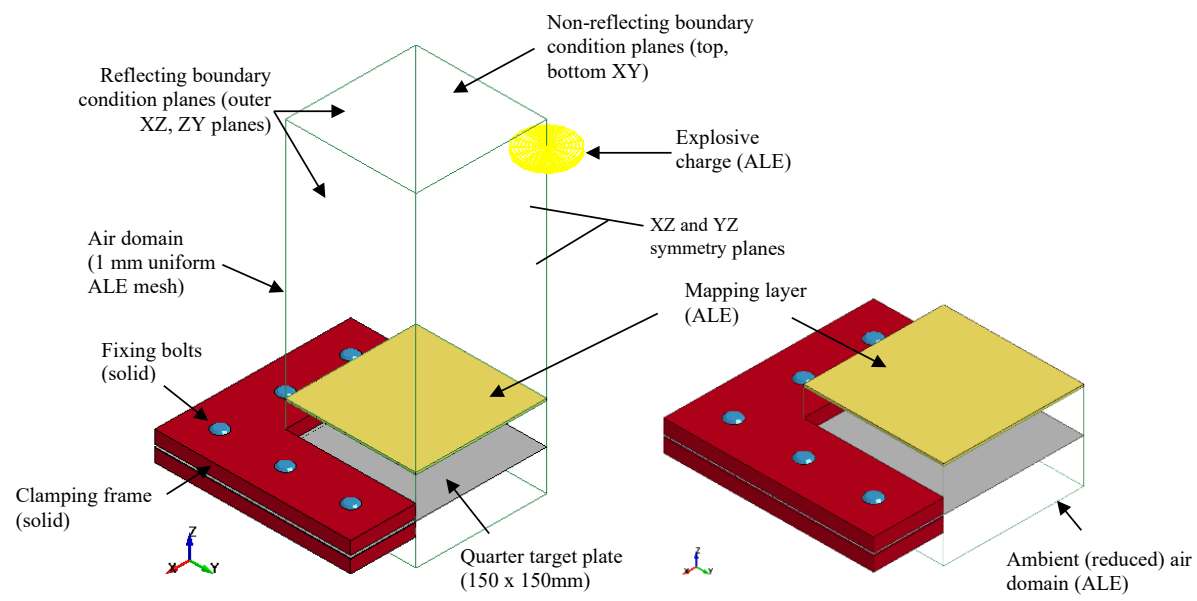

(a) Full ALE air and explosive model

(b) Reduced model (ALE mapping method)

Fig. 2. Model components with quarter symmetry boundary conditions

\subsection{Modelling of CFRP retrofitted steel plate}

CFRP retrofitted steel plates were modelled using the *PART_STACKED_ELEMENTS (PSE) keyword. The PSE feature enabled for the creation of a stacked model for shell-like structures, which was used to model composite structures such as sandwich plate systems and composite laminates [17, 19]. Fig. 3 illustrates the retrofitted plate components.

The CFRP retrofitted steel plate was modelled as a sequence of shell elements and solid elements using the PSE feature. For plate modelling, the steel and CFRP layers were meshed with $2 \times 2 \mathrm{~mm} 4$-node Belytschko-Tsay shell elements (ELFORM=2) with $1 \mathrm{~mm}$ and 0.176 $\mathrm{mm}$ thicknesses, respectively. The $2 \times 2 \mathrm{~mm}$ element size was selected based on the findings 
of a previous mesh sensitivity research [20] and numerical simulation [21] of plates subjected to near-field blast loads. To capture layer delamination, the cohesion between the shell layers was modelled by inserting $2 \times 2 \times 0.15 \mathrm{~mm} 8$-node solid cohesive elements between the steel plate and CFRP layers. The steel frame and bolts were modelled with coarse mesh of solid elements with typical side length of 5mm. *CONTACT_AUTOMATIC_NODES_TO_SURFACE / SURFACE_TO_SURFACE cards were used to simulate the contact between the target and the bolts, and the contact between the target and the frame.

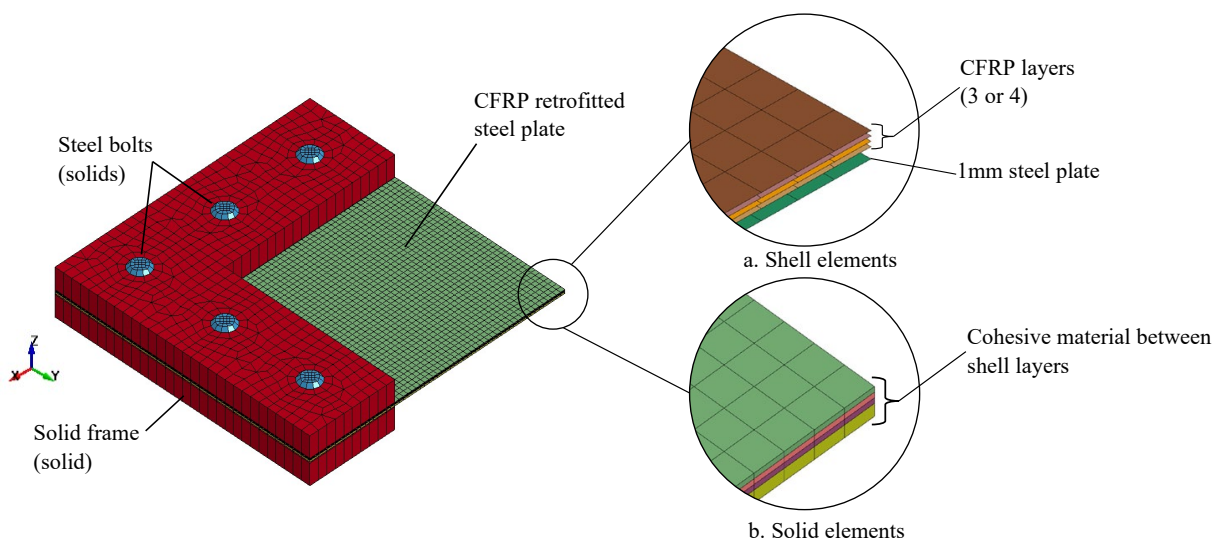

Fig. 3. Components of CFRP retrofitted steel plate modelled using PSE feature

\subsubsection{Material properties for steel material}

The Johnson-Cook (JC) plasticity material model (MAT_015) was selected to model the steel shell elements. The flow stress was expressed by the JC model as in Eq. 1, where $\sigma_{y}$ is the von Mises flow stress, $\bar{\varepsilon}^{p}$ is the effective plastic strain, $\dot{\varepsilon}^{*}=\dot{\varepsilon} / \dot{\varepsilon}_{0}$ is the dimensionless plastic strain rate for $\dot{\varepsilon}_{0}=1.0 \mathrm{~s}^{-1}$, and $T^{*}$ is the homologous temperature. The material constants in Eq. 1 are $A$ (the yield stress), $B$ and $n$ (represents the effects of strain hardening), $C$ (the strain rate constant) and $m$ (temperature constant).

The average yield stress of the quasi-static uniaxial tensile tests was used to calculate parameter $A$. The parameters $B$ and $n$ were calculated by fitting the strain hardening part (which includes $A, B$ and $n$ ) of Eq. 1 to the experimental true stress-strain curve, with $A$ set to the average yield stress of steel. The JC input data used for $A, B$ and $n 267.8 \mathrm{MPa}, 23.4$ $\mathrm{MPa}$ and 0.65 respectively. Values of the strain rate and temperature constants were taken from Refs. $[22,23]$ as further data for the steel used were not available. The input data used for $C$ and $m$ were 0.014 and 1.03 respectively.

$$
\sigma_{y}=\left(A+B \bar{\varepsilon} p^{n}\right)\left(1+C \ln \dot{\varepsilon}^{*}\right)\left(1+T^{* m}\right)
$$

\subsubsection{CFRP modelling}

To simulate the mechanical behaviour of the unidirectional CFRP material, the enhanced composite damage material model (MAT_054) was used. Previous research [24, 25] used the MAT_054 material model to evaluate the response of FRP composite materials to impact and blast loads, demonstrating a good degree of accuracy. In MAT_054, the Chang-Chang failure criterion was implemented, and the corresponding layer in the element was removed after the maximum fibre tensile strain was met. For modelling the cohesive elements, the cohesive mixed-mode material (MAT_138) was selected, which was characterised by a bilinear traction-separation law (TSL) with a quadratic mixed mode delamination criterion. In this 
study, experiments were not carried out to characterise the mechanical properties of the CFRP and epoxy materials (e.g., tensile strength, maximum tensile strain). The MAT_054 input data for the unidirectional CFRP from Ref. [26] and the MAT_138 input data for epoxy from Ref. [27] were applied in the model.

\subsection{Blast modelling - ALE mapping}

The ALE mapping method in LS-DYNA was used to simulate the blast load located close to target using the MM-ALE approach while saving significant computational time. Using the mapping approach, blast pressures obtained by explicit MM-ALE modelling of explosive and air were applied to a layer of ALE elements (known as the mapping layer) facing the explosive charge. The pressures of ALE elements obtained in the mapping layer were saved and applied in another model that included the remaining of the air domain and the structure (known as the reduced model). The ALE mapping approach was implemented in two stages: (i) generating pressure data for a selected ALE mapping layer in a full MM-ALE model (explicit air and explosive); (ii) using the pressure data received in the first step from the ALE mapping layer and apply it to a model that includes the remaining MM-ALE air domain (aironly). A different LS-DYNA model was used for each stage.

\subsubsection{First stage - Blast pressure generation in ALE mapping}

A full ALE air-domain model was modelled to generate the blast pressures resulting from explicitly modelling the explosive with the geometrical properties considered in the experiment. The *INITIAL_VOLUME_FRACTION_GEOMETRY was used to define the air and explosive materials in the same mesh. Fraction background of ALE explosive material was defined as cylinder with $40 \mathrm{~mm}$ diameter and heights that corresponded to those used in the experiment, as shown in Fig. 2 (a).

A uniform fine mesh of hexahedral elements and side length of $1 \mathrm{~mm}$ was used to model the air domain $(2,430,000$ 8-node solid element). The element size for the air domain was determined by the findings of a previous mesh sensitivity study [20]. The linear polynomial equation of state (EOS) was used to model air as an ideal gas, while the MAT_008 and JohnWilkins-Lee EOS were used to characterise the PE-C4 explosive. The MAT_008 and JWL EOS input data used were similar to those in Ref. [22].

The mapping layer was situated $18 \mathrm{~mm}$ away from the target plate and was modelled as a one-element thick layer of ALE elements. *BOUNDARY_ALE_MAPPING (BAM) keyword was used to write a mapping file that stores the blast pressure histories of the mapping layer ALE elements. IVOLTYP=2 was set in BAM keyword to direct the software to write the data of ALE elements, included in a box shape, in the mapping file. A termination time of $0.25 \mathrm{~ms}$ was used to write the data in the mapping file, which was selected to ensure that the blast pressures are fully generated.

\subsubsection{Second stage - Blast pressure application in ALE mapping}

In the second stage, the output mapping file generated from the first stage was used as input mapping file in the reduced air-domain model The pressure data saved in the mapping file were imposed in the mapping layer (Fig. 2 (b)) and used as a source for adjoining ALE air elements. In the reduced model, a uniform mesh of hexahedral elements with a side length of $1 \mathrm{~mm}$ was also used. The ALE air domain surrounded the Lagrangian structure, and fluid structure interaction (FSI) controlled the interaction of the generated blast pressures with the structure. The use of the mapping technique resulted in a significant reduction in model size, with the number of ALE air domain elements reduced to 230,000 (by 95\%). 


\section{Results and Discussions}

\subsection{Blast pressure results}

Fig. 4 illustrates the pressures for the blast wave transmitted by the detonation of a $9 \mathrm{~g}$ charge at different time instants in the mapped model. It was found from the simulation that the pressure values produced from the reduced air domain and applying the mapped pressure layer are nearly identical to those obtained from the full air domain. The reflected pressures on the plate mid-point recorded from the simulation for $7 \mathrm{~g}, 9 \mathrm{~g}$ and $13 \mathrm{~g}$ charges is shown in Fig. 5 (a). In the simulation, pressure curves showed a positive pressure phase with a peak reflected pressure that occurred rapidly (arrival time of 42-45 $\mu \mathrm{s}$ ) and for very short durations (200 $\mu$ s approx.). The predicted peak pressures increased with explosive charge mass, ranging from 87.1 to $147.9 \mathrm{MPa}$.

The pressures were validated by comparing impulses reflected by the target plate with experimental results. The reflected impulse was evaluated using a rigid target plate in the model. The simulated impulse-time histories for the $7 \mathrm{~g}, 9 \mathrm{~g}$, and $13 \mathrm{~g}$ charges are shown in Fig. 5 (b). The simulated impulse values are shown in Table 1, and they were found to correlate well with the experiment results, with a variation margin of less than $10 \%$.

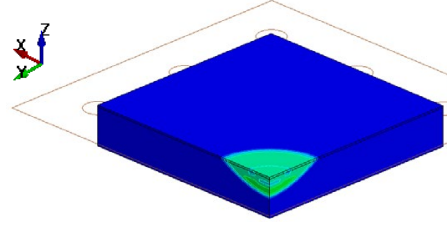

$40 \mu \mathrm{s}$

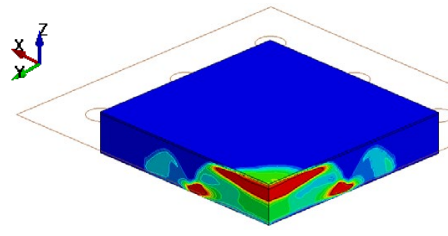

$60 \mu \mathrm{s}$
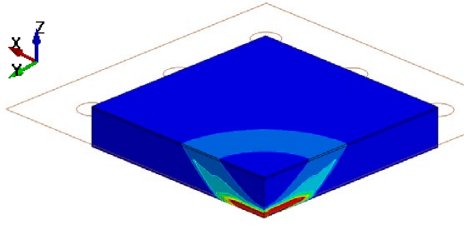

$45 \mu \mathrm{s}$
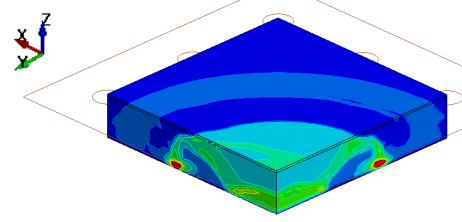

$70 \mu \mathrm{s}$

Fig. 4. Blast wave pressures (in $\mathrm{Pa}$ ) in the mapped model at various time instants for $9 \mathrm{~g}$ charge mass

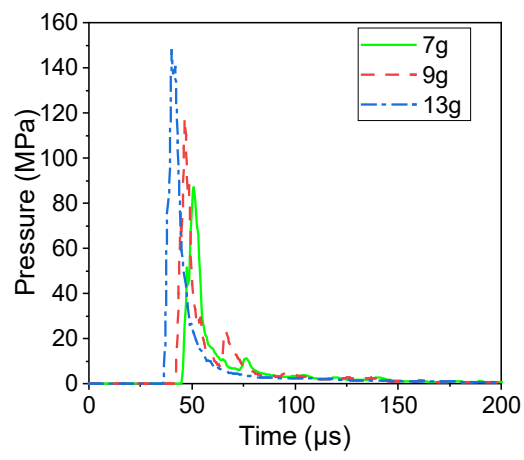

(a)

Fig. 5. Simulation results of the blast wave properties: (a) pressure-time histories at the centre of the target plate, (b) Numerical (Num) and Experimental (Exp) impulse-time histories 


\subsection{Deformations in bare steel plates}

The failure mode observed in the experiment and the simulation was the Mode I (large inelastic deformation) in square uniformly blast loaded plates [28]. The simulated deformed shapes of bare steel specimens in the blast testing are plotted in Fig. 6 (a). The plastic strains in the simulation shown in Fig. 6 (b) predicted the yielding regions, including the plate middle region and the at the boundaries, as well as the elongation in bolt holes. Figure 7 (a) depicts the residual deformation of a bare specimen subjected to a $13 \mathrm{~g}$ explosive mass blast. Fig.7 (b) presents the simulated deflection histories of bare specimens. The simulation showed that steel plate behaved almost linearly with time to a large deformation, reaching a maximum and then exhibiting a minor amount of residual elastic vibration around a mean displacement after around $500 \mu \mathrm{s}$. The results of a comparison of the simulated mid-point displacement and the experimental data are shown in Table 2. It can be observed that the results show very good correlation with a margin of variation less than $5 \%$.
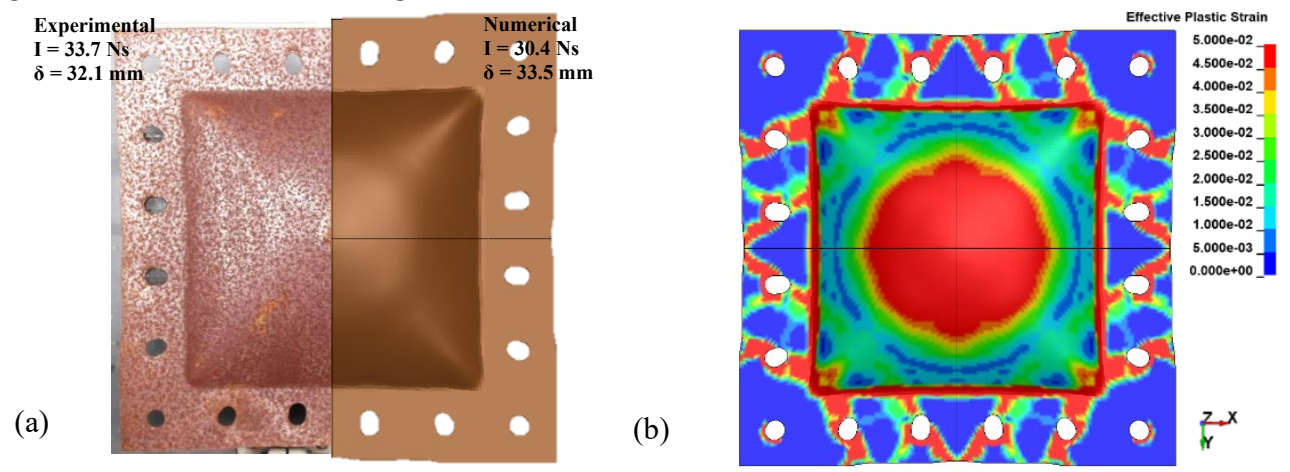

Fig. 6. Comparison of numerical simulation results with experimental results for $13 \mathrm{~g}$ charge: (a) overlook view; (b) effective plastic strains

(a)

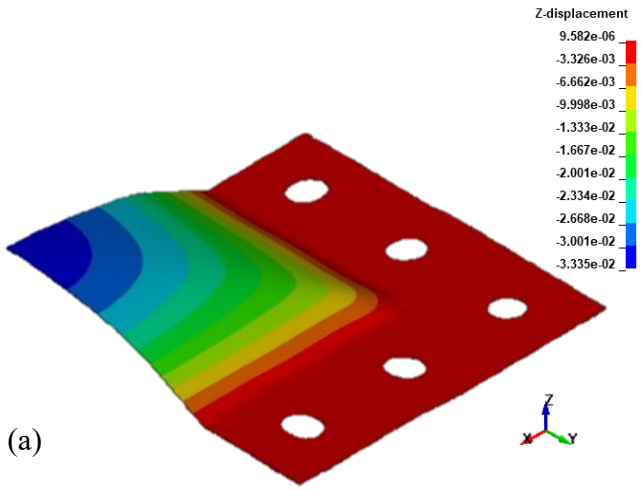

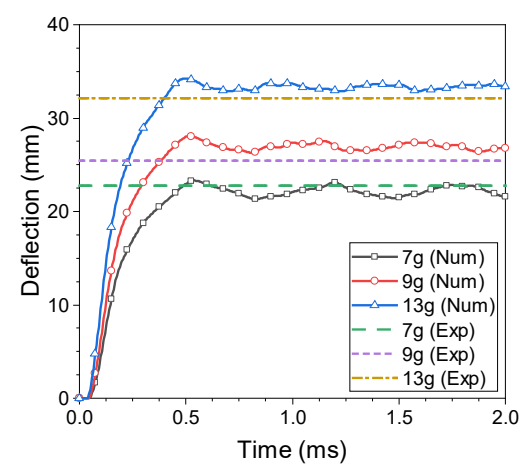

(b)

Fig. 7. Numerical results for bare specimens: (a) final deformed shape - quarter plate for $13 \mathrm{~g}$ (impulse $=30.4 \mathrm{Ns}$, displacement in metres), (b) mid-point displacement histories

\subsection{Deformations in CFRP retrofitted steel plates}

\subsubsection{Comparison of CFRP retrofitted steel plate deformation}

For the CFRP retrofitted steel plates, numerical simulations were performed, and predictions of plate deformation were compared to the experiment for validation. In the experiment and simulation, the steel plate profiles in the CFRP retrofitting specimens all 
experienced Mode I failure, but with less transverse deflections than bare specimens. Fig. 8 illustrates comparison between the experimental and the simulated deformation of steel in 3layer CFRP (CB) and steel blast-faced (SB) retrofitted specimens for $13 \mathrm{~g}$ charge. The experimental results showed that the bonded CFRP effectively reduced the plate deformation. For 3-layer CFRP retrofitted specimens, the plate deflection decreased relative to bare plates by $42 \%$ to $52 \%(9.6-14.1 \mathrm{~mm})$.

Further reduction in deflections was observed in 4-layer CFRP retrofitted plates relative to bare and 3-layer CFRP retrofitted specimens, where 4-layer CFRP retrofitted specimens demonstrated a further reduction in deflection relative to bare plates by $50 \%$ to $64 \%$ (13.2$19.2 \mathrm{~mm}$ ). The effect of the blast-facing material (i.e., CFRP or steel) was more evident in 4layer CFRP retrofitting specimens, where the mid-point displacement of SB specimens was 0.1 to $3.3 \mathrm{~mm}$ lower than that of $\mathrm{CB}$ specimens.

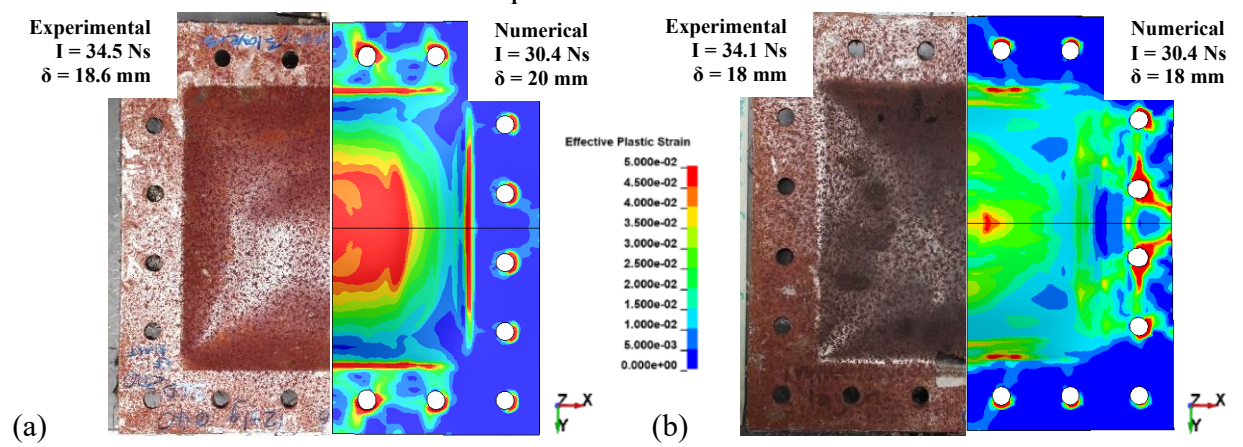

Fig. 8. Comparison of deformation between experimental and numerical results for 3-layer CFRP retrofitted plates for 13g: (a) CFRP blast-faced specimen (bottom); (b) steel blast-faced specimen (top)

(a)

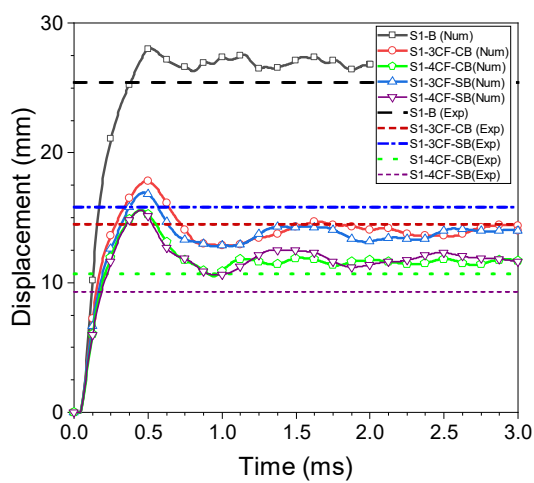

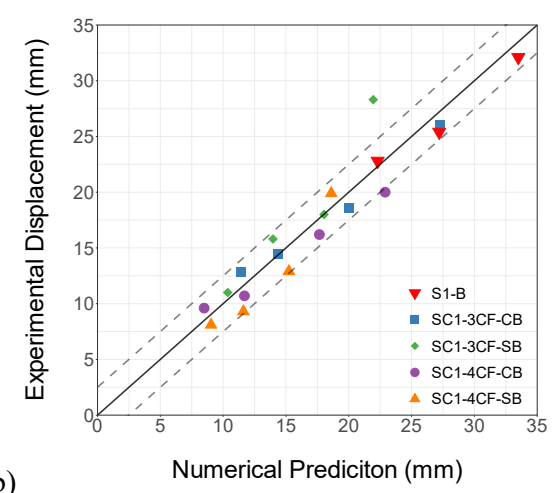

(b)

Fig. 9. Numerical results (a) mid-point displacement histories of bare and CFRP retrofitted specimens for $9 \mathrm{~g}$ charge, (b) comparison of experimental and numerical mid-point displacements

Similar findings were obtained from the simulation in general, as illustrated in Fig. 9 (a) for the comparison of the mid-point displacement histories obtained from the simulations of bare and CFRP retrofitted steel plates for 9g charge. The displacement trends in Fig. 9 (a) indicated that the steel plates in the retrofitted panels obtained lower maximum deformation and residual elastic vibration levels than bare steel specimens due to CFRP retrofitting. The simulation for the mid-point deflection is plotted against the experimental data and is shown in Fig. 9 (b). The numerical model reasonably predicted the mid-point deflection of CFRP retrofitted plates, with 90 percent of the simulated displacements estimating the experimental within a $\pm 2.5 \mathrm{~mm}$ (or $20 \%$ ) variation range. The numerical results followed a similar pattern as the experimental data. Table 1 summarises the experimental and numerical results. 
Table 1. Summary of experimental and numerical results

\begin{tabular}{|c|c|c|c|c|c|c|c|c|}
\hline Specimen & $\begin{array}{l}\text { Mass of } \\
\text { PE4 } \\
(\mathrm{g})\end{array}$ & $\begin{array}{l}\text { Blasted } \\
\text { side }\end{array}$ & $\begin{array}{l}\text { CFRP } \\
\text { No. of } \\
\text { layers }\end{array}$ & $\begin{array}{l}\text { Experimental } \\
\text { Impulse } \\
(\mathrm{Ns})\end{array}$ & $\begin{array}{l}\text { Experimental } \\
\text { mid-point } \\
\text { displacment } \\
(\mathrm{mm})\end{array}$ & $\begin{array}{l}\text { Numerical } \\
\text { Impulse } \\
\text { (Ns) }\end{array}$ & $\begin{array}{l}\text { Numerical } \\
\text { mid-point } \\
\text { displacment } \\
(\mathrm{mm})\end{array}$ & $\begin{array}{l}\text { Displacement } \\
\text { variation } \\
(\%)\end{array}$ \\
\hline S1-B-07 & 7 & Steel & - & 21.7 & 22.8 & 21.1 & 22.3 & -2.2 \\
\hline S1-B-09 & 9 & Steel & - & 25.1 & 25.4 & 25.7 & 27.2 & 7.1 \\
\hline S1-B-13 & 13 & Steel & - & 33.7 & 32.1 & 30.4 & 33.5 & 4.4 \\
\hline SC1-3CF-CB-07 & 7 & CFRP & 3 & 20.9 & 12.8 & 21.1 & 11.5 & -10.5 \\
\hline SC1-3CF-CB-09 & 9 & CFRP & 3 & 25.5 & 14.5 & 25.7 & 14.4 & -1.0 \\
\hline SC1-3CF-CB-13 & 13 & CFRP & 3 & 34.5 & 18.6 & 30.4 & 20.0 & 7.7 \\
\hline SC1-3CF-CB-16 & 16 & CFRP & 3 & 38.8 & 26 & 35.4 & 27.3 & 4.8 \\
\hline SC1-3CF-SB-07 & 7 & Steel & 3 & 21.3 & 11 & 21.1 & 10.4 & -5.8 \\
\hline SC1-3CF-SB-09A & 9 & Steel & 3 & 27.6 & 15.8 & 25.7 & 14.0 & -11.6 \\
\hline SC1-3CF-SB-09B & 9 & Steel & 3 & 25.7 & 14.3 & 25.7 & 14.0 & -2.3 \\
\hline SC1-3CF-SB-13 & 13 & Steel & 3 & 34.1 & 18 & 30.4 & 18.0 & 0.2 \\
\hline SC1-3CF-SB-16 & 16 & Steel & 3 & 36.9 & 28.3 & 35.4 & 21.9 & -22.4 \\
\hline SC1-4CF-CB-07 & 7 & CFRP & 4 & 23.5 & 9.6 & 21.1 & 8.5 & -11.6 \\
\hline SC1-4CF-CB-09 & 9 & CFRP & 4 & 27.1 & 10.7 & 25.7 & 11.7 & 9.3 \\
\hline SC1-4CF-CB-13 & 13 & CFRP & 4 & 33.9 & 16.2 & 30.4 & 17.7 & 9.0 \\
\hline SC1-4CF-CB-16 & 16 & CFRP & 4 & 38.6 & 20 & 35.4 & 22.9 & 14.5 \\
\hline SC1-4CF-SB-07 & 7 & Steel & 4 & 21.1 & 8.1 & 21.1 & 9.0 & 11.6 \\
\hline SC1-4CF-SB-09 & 9 & Steel & 4 & 25.9 & 9.3 & 25.7 & 11.6 & 24.9 \\
\hline SC1-4CF-SB-13 & 13 & Steel & 4 & 33.9 & 12.9 & 30.4 & 15.2 & 18.1 \\
\hline SC1-4CF-SB-16 & 16 & Steel & 4 & 40.1 & 19.9 & 35.4 & 18.6 & -6.5 \\
\hline
\end{tabular}

\subsubsection{Damage modes in CFRP}

For CFRP, the experimental results showed combined FRP failure modes due to uniform blast loads including metal-FRP debonding, delamination/tearing, fibre rupture and matrix failure. Fig 10 (a) shows the typical FRP modes as obtained from the experiment. In CFRP blast-faced specimens, CFRP demonstrated a complex response where metal-fibre debonding, delamination and longitudinal tearing modes were exhibited at lower impulses. For steel blast-faced specimens, the damage shown by CFRP included metal-fibre debonding, longitudinal tearing at the plate boundaries parallel to fibres as shown in Fig. 10 (a). Fibre fracture in the plate boundaries crossing the fibre direction was observed at higher impulses.

The simulated model predicted the major failure modes in CFRP including the matrix failure, FRP fracture and metal-FRP debonding. For example, Fig. 10 (b) depicts the numerical deformation in a CFRP blast-faced retrofitted specimen for $16 \mathrm{~g}$, where the model predicted metal-FRP debonding that agreed with experiment observations. Despite capturing the major failure modes, the simulation underestimated FRP fracture at the boundaries observed in steel blast-faced specimens, and metal-FRP debonding was extended across a wider area than the experiment revealed. The discrepancy in CFRP damage observed in the simulation could be attributed to the fact that values used in various parameters of the CFRP and adhesive material models (e.g., failure strain) used in the simulation might differ from the actual mechanical properties of these materials.

However, the simulation was still able to provide a better understand for the failure mechanism. Fig. 11 shows a comparison of the simulated and experimental deformation in steel blast-faced retrofitted specimens for $16 \mathrm{~g}$. The CFRP damage occurred in the experiment at the plate boundaries in the form of FRP fracture in the direction perpendicular to fibres and delamination in the fibre direction. The numerical model captured the failure zone, where the damage was indicated by the von Misses stress as shown in Fig. 11 (b), which corresponded with the experimental observation in general. 


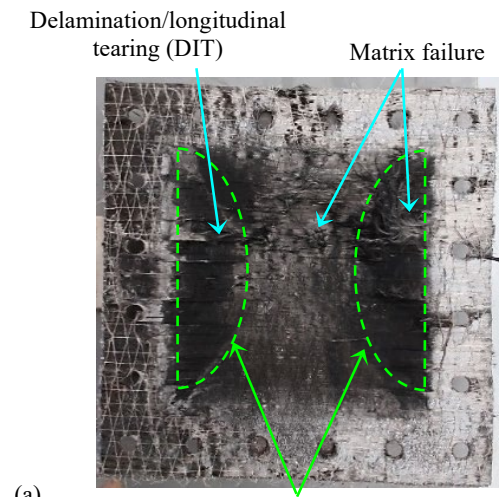

(a)

$$
\text { Metal-fibre debonding (MFD) }
$$

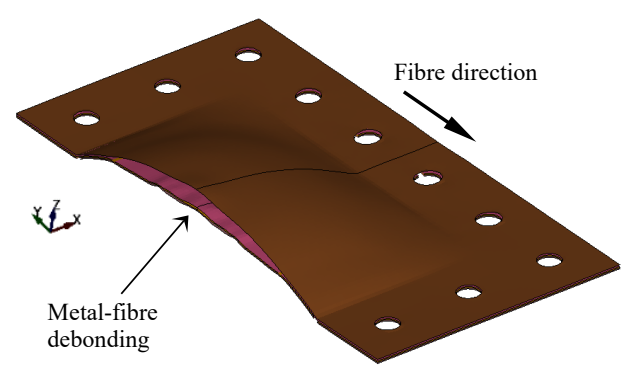

(b)

Fig. 10. Comparison of CFRP damage between experiment and simulation (3-Layer CFRP, CFRP blasted-side, 16g): (a) typical damage modes (experimental); (b) damage in cross-section (numerical)

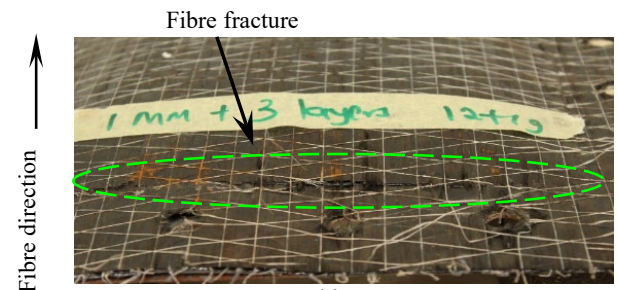

(a)

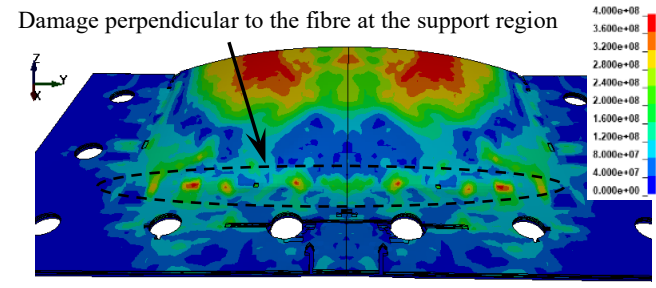

(b)

Fig. 11. Comparison of CFRP damage at supports between experiment and simulation (3-Layer CFRP, steel blasted-side, 13g): (a) experiment; (b) simulation

\subsection{Comparison of computational time}

Fig. 12 compares the CPU (central processing unit) elapsed time required to conduct the analysis using various methods. Using an SMP (Shared Memory Parallel) LS-DYNA solver in a single machine (Intel ${ }^{\circledR}$ Core $^{\mathrm{TM}} \mathrm{i} 5$ ), The time required to complete the analysis of $2 \mathrm{msec}$ analysis termination time for the full air-domain model was 730296 CPU seconds (8 days, 10 hours). The use of a reduced air-domain model with mapped layer allowed for a $95 \%$ reduction in elapsed time in the full model, as the mapped model required $36139 \mathrm{CPU}$ seconds (10 hours) to complete the analysis of a similar termination time. The effectiveness of the mapping technique was further evaluated by executing an analysis of the whole airdomain model using the LS-DYNA MPP (Massively Parallel Processing) solver on a highperformance computer (HPC). The CPU elapsed time required for $2 \mathrm{msec}$ termination time using MPP solver and 32 cores ( 4 nodes, 8 cores per node) was 27664 ( 7 hours, 41 minutes), lowering the analysis time using SMP solver by $96 \%$. Hence, the use of mapping techniques appeared to provide significant computational savings when using an SMP solver.

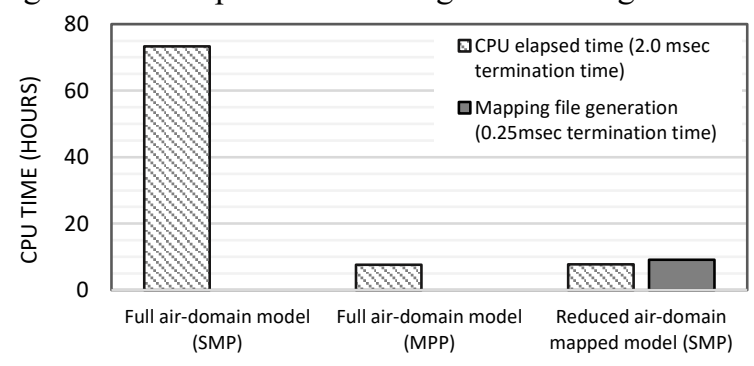

Fig. 12. Comparison of CPU elapsed time for the analysis 


\section{Conclusions}

This paper reports on the results of a numerical study to simulate the response of carbon fibre reinforced polymer (CFRP) retrofitted steel plates due to blast loads using finite element software, LS-DYNA. The results of the simulation were validated against plate response and magnitude of deformation obtained from experiments. When using the SMP solver, the use of a reduced air-domain model with mapped layer allowed for a 95\% reduction in CPU elapsed time in the model simulated with fine air mesh. The use of PSE feature provided savings in the time and efforts required to model the composite plates. Displacement histories obtained from the analysis indicated satisfactorily estimates for actual residual deflections with variation range of $\pm 20 \%$. For damage modes in analysed retrofitted specimens, the steel plate exhibited large inelastic deformation which agreed with actual failure modes found experimentally. While for CFRP layers, the simulated model captured the main damage features that include fibre-steel debonding, fibre fracture and delamination in CFRP layers. The use of the LS-DYNA mapping approach for blast application and PSE for composite plate modelling resulted in a satisfactory prediction of CFRP-steel composite plate response under blast while saving significant computational time.

Acknowledgments: Part of the LS-DYNA computations were performed using facilities provided by the University of Cape Town's ICTS High Performance Computing team: hpc.uct.ac.za.

\section{References}

[1] L. Hollaway, "A review of the present and future utilisation of FRP composites in the civil infrastructure with reference to their important in-service properties," Construction and Building Materials, vol. 24, no. 12, pp. 2419-2445, 2010.

[2] X.-L. Zhao, FRP-strengthened metallic structures. CRC Press, 2013.

[3] A. I. Danilov, "Some Aspects of CFRP Steel Structures Reinforcement in Civil Engineering," Procedia Engineering, vol. 153, pp. 124-130, 2016.

[4] J. Teng, T. Yu, and D. Fernando, "Strengthening of steel structures with fiberreinforced polymer composites," Journal of Constructional Steel Research, vol. 78, pp. 131-143, 2012.

[5] H. Draganić, G. Gazić, and D. Varevac, "Experimental investigation of design and retrofit methods for blast load mitigation - A state-of-the-art review," Engineering Structures, vol. 190, pp. 189-209, 2019.

[6] P. A. Buchan and J. F. Chen, "Blast resistance of FRP composites and polymer strengthened concrete and masonry structures - A state-of-the-art review," Composites Part B: Engineering, vol. 38, no. 5, pp. 509-522, 2007.

[7] A. P. Mouritz, "Advances in understanding the response of fibre-based polymer composites to shock waves and explosive blasts," Composites Part A: Applied Science and Manufacturing, vol. 125, p. 105502, 2019.

[8] X. Zhao and R. Al-Mahaidi, "A brief review of CRP-metal systems subjected to impact and blast loading," presented at the 23rd Australasian Conference on the Mechanics of Structures and Materials (ACMSM23), Byron Bay, Australia, 9-12 December 2014, 2014.

[9] M. R. Bambach, X. L. Zhao, and H. Jama, "Energy absorbing characteristics of aluminium beams strengthened with CFRP subjected to transverse blast load," International Journal of Impact Engineering, vol. 37, pp. 37-49, 2010.

[10] D. J. Stevens, J. M. H. Puryear, N. Smith, and M. H. Gomez, "Effects of close-in charges on pipeline components," in Structures Congress 2012, pp. 102-113.

[11] M. Mokhtari and A. Alavi Nia, "The application of CFRP to strengthen buried steel pipelines against subsurface explosion," Soil Dynamics and Earthquake Engineering vol. 87, pp. 52-62, 2016. 
[12] F. Dolce, M. Meo, A. Wright, M. French, and M. Bernabei, "Structural response of laminated composite plates to blast load," Plastics, Rubber and Composites, vol. 39, no. 3-5, pp. 180-188, 2010.

[13] D. Karagiozova, G. S. Langdon, G. N. Nurick, and S. Chung Kim Yuen, "Simulation of the response of fibre-metal laminates to localised blast loading," International Journal of Impact Engineering, vol. 37, no. 6, pp. 766-782, 2010.

[14] E. Sitnikova, Z. W. Guan, and W. J. Cantwell, "The analysis of the ultimate blast failure modes in fibre metal laminates," Composites Science and Technology, vol. 135, pp. 1-12, 2016.

[15] J. Li, C. Huang, T. Ma, X. Huang, W. Li, and M. Liu, "Numerical investigation of composite laminate subjected to combined loadings with blast and fragments," Composite Structures, vol. 214, pp. 335-347, 2019.

[16] N. Aquelet and M. Souli, "2D to 3D ALE mapping," in 10th International LS-DYNA Users Conference, 2008, pp. 23-34.

[17] "LS-DYNA Keyword User's Manual," Livermore Software Technology Corporation (LSTC), Livermore, California, United States of America2017.

[18] T. P. Slavik, "A Coupling of Empirical Explosive Blast Loads to ALE Air Domains in LS-DYNA ${ }^{\circledR}, "$ IOP Conference Series: Materials Science and Engineering, vol. 10, no. 1, p. 012146, 2010.

[19] T. Erhart, "A New Feature to Model Shell-Like Structures with Stacked Elements," in 10th European LS-DYNA Conference 2015, Würzburg, Germany, 2015.

[20] C. Geretto, "The Effects of Different Degress of Confinement on the Deformation of Square Plates Subjected to Blast Loading," PhD Thesis, University of Cape Town, Cape Town, 2012.

[21] S. Rigby et al., "Predicting the response of plates subjected to near-field explosions using an energy equivalent impulse," International Journal of Impact Engineering, vol. 128, pp. 24-36, 2019.

[22] S. Chung Kim Yuen, G. N. Nurick, and H. B. Brinckmann, "Response of Cylinderical Shells to Lateral Blast loads," International Journal of Protective Structures, vol. 4, no. 3, pp. 209-230, 2013.

[23] "ANSYS/Autodyn version 11.0, User Documentation," Century Dynamics Inc., a subsidiary of ANSYS Inc.2007.

[24] C. Reuter and T. Tröster, "Crashworthiness and numerical simulation of hybrid aluminium-CFRP tubes under axial impact," Thin-Walled Structures, vol. 117, no. Supplement C, pp. 1-9, 2017.

[25] F. Dolce, "Blast impact simulation on composite military armours," Master of Philosophy dissertation, University of Bath, 2009.

[26] P. Feraboli, B. Wade, F. Deleo, M. Rassaian, M. Higgins, and A. Byar, "LS-DYNA MAT54 modeling of the axial crushing of a composite tape sinusoidal specimen," Composites Part A: applied science and manufacturing, vol. 42, no. 11, pp. 18091825, 2011.

[27] S. Muflahi, G. Mohamed, and S. Hallett, "Investigation of Delamination Modeling Capabilities for Thin Composite Structures in LS-DYNA," in Advanced Composites Centre for Innovation and Science, 13th International LS-DYNA Users Conference, 2014, vol. 70.

[28] G. N. Nurick and G. C. Shave, "The deformation and tearing of thin square plates subjected to impulsive loads-An experimental study," International Journal of Impact Engineering, vol. 18, no. 1, pp. 99-116, 1996. 